\title{
ARTICLES
}

\section{Response of Nasopharyngeal Carcinoma Cells to Epstein-Barr Virus Infection In Vitro}

\author{
Chin-Tarng Lin, Hsiao-Jung Kao, Jau-Liang Lin, Wing-Yee Chan, Han-Chung Wu, \\ and Sung-Tzu Liang \\ Institute of Pathology, College of Medicine, National Taiwan University, Taipei, Taiwan, Republic of China
}

SUMMARY: Many nasopharyngeal carcinoma (NPC) biopsy specimens contain Epstein-Barr virus (EBV). However, the response of NPC cells to EBV infection in vitro and in vivo is not well characterized. In this experiment we infected NPC cells with EBV particles through endocytosis of a complex of EBV immunoglobulin A (IgA) secretory component (SC) protein to observe the response of host cells to the foreign viral infection in vitro. We found that EBV particles were endocytosed and stabilized in NPC nuclei 24 hours after infection; the EBV genomes were then gradually decreased after serial passages within 3 to 4 weeks by the following pathway: the EBV genomes first moved toward the nuclear envelope from the center of the nucleus; after crossing the nuclear envelope, they moved into the cytoplasm and toward the plasma membrane and were discharged by exocytosis. At the 10th day of EBV infection, EBV-latent membrane protein-1 and Epstein-Barr nuclear antigen (EBNA)-1 protein expressions could be detected, but not EBV-viral capsid antigen. Observation of EBNA-1 protein and host growth factor and cytokine gene expressions in the weeks after incubation revealed that the EBNA-1 protein expression was decreased proportionally with decrease of EBV genome. The mRNA expression of epithelial growth factor receptor, transforming growth factor (TGF)- $\alpha$, interleukin (IL)-1 $\beta$, IL-6, and granulocyte-macrophage colony-stimulating factor increased within 1 to 2 weeks after infection, and gradually recovered to the original level at 3 to 4 weeks, whereas the mRNAs of TGF $\beta 1$, TGF $\beta$ receptor type I (TGF $\beta$ RI), TGF $\beta$ R type II, IL-8, and tumor necrosis factor- $\alpha$ remained unchanged. It is concluded that in vitro EBV infection in NPC cells results in increase of certain growth factor and cytokine gene expressions in host cells. The change in gene expression returns to the original level approximately 3 to 4 weeks after infection because of exocytosis of EBV DNA by the infected cells through an unidentified mechanism. (Lab Invest 2000, 80:1149-1160).

$N$ asopharyngeal carcinoma (NPC) is one of the most common cancers among Chinese living in Taiwan, Singapore, and South China (Chan, 1990; de The, 1982; Lin et al, 1971). The etiological factors for this cancer are not yet well defined. Epstein-Barr virus (EBV) has been suggested to be closely associated with NPC (Ablashi et al, 1991; Klein et al, 1974; Niedobitek et al, 1991; Zur Hausen et al, 1970). Hereditary and other environmental factors, such as eating salted fish and exposure to sulfuric acid vapor, have also been associated with NPC (Armstrong et al, 1983; Hirayama and Ito, 1981; Ho et al, 1999).

For identification of the actual relationship between EBV and NPC, we have previously established nine NPC cell lines in our laboratory (Lin et al, 1990, 1993).

Received December 10, 1999.

This work was supported in part by research grants from National Health Research Institute (DOH88-HR-710) and from the National Science Council (NSC88-2314-B002-176), Taiwan, and a clinical research grant to C.T. Lin (1996) from National Taiwan University Hospital, Taipei, Taiwan.

Address reprint requests to: Dr. Chin-Tarng Lin, Department of Pathology, National Taiwan University Hospital, Taipei 100, Taiwan. Fax: 8862-2382-6649; E-mail: ctl@ha.mc.ntu.edu.tw
Results from the observation of EBV in these nine NPC cell lines and biopsy specimens revealed that EBV was present in only five of nine lines and was an episomal, but not an integrated form, in the infected cells. In each EBV-infected cell line, only a small fraction of the cell population contained EBV DNA. In biopsy specimens, EBV did not appear in untransformed squamous metaplastic cells, but it did appear in certain NPC cells and tumor-infiltrating lymphocytes. The EBV-infected tumor cells revealed a geographical pattern similar to a picture of clonal expansion surrounded by EBV-negative NPC cells (Lin et al, 1994). NPC tumor cells did not express EBV receptor (C3d receptor), but they seemed to serve as polymeric immunoglobulin receptors [secretory component (SC)] in certain tumor cells. SC was also not expressed in the untransformed squamous metaplastic epithelial cells. EBV could infect SC-positive NPC cells through EBV-immunoglobulin A ( $\lg \mathrm{A})$-SC mediated endocytosis and be stabilized in the nuclei of the infected cells. EBV genomes gradually decreased in the infected tumor cells after serial passages by an unknown mechanism. In the EBVinfected tumor cells, the SC protein expression was suppressed gradually, probably by EBV protein prod- 
uct directly or indirectly (Lin et al, 1997b). Clonal EBV terminal repeat DNA sequence was identified in EBVinfected NPC cells in vitro (Lin et al, 1997a).

Clinically, NPC patients frequently show a high titer of IgA antibody against EBV antigens, such as viral capsid antigen (VCA) and early antigen (EA). In many cases, the $\lg A$ titer against EBV-VCA is elevated following the enlargement or recurrence of NPC tumor mass and is decreased when the tumor mass becomes smaller after radiotherapy (Pearson, 1993; Takada et al, 1995; Wolf et al, 1993). However, it is not clearly known why the IgA titer anti-EBV changes after the tumor mass becomes larger or smaller. It is also not known why the EBV-infected NPC cells proliferate faster than the EBV-negative NPC cells, resulting in a clonal expansion of EBV-positive tumor cells within the tumor mass (Lin et al, 1994, 1997b). EBV-infected NPC cells have been shown to express EB nuclear antigen-1 (EBNA-1), latent membrane protein (LMP)-1, LMP-2A, and LMP-2B, and all of them have transactivation function (Nemerow and Cooper, 1981; Pearson, 1993), but no clear evidence has been demonstrated that direct EBV infection induces or suppresses expression of NPC cellular growth factors and cytokines. In the present study, we have performed experiments to identify the pathway of EBV genomic loss during subculture and the reasons for this loss and to demonstrate the changes of expression of certain growth factors and cytokines in response to EBV infection.

\section{Results}

\section{Identification of EBV DNA in Infected NPC Cells}

When in situ PCR hybridization was used to identify EBV DNA in the EBV-infected cells, many granular reaction products of EBV DNA signal were seen clustered in each infected cellular nucleus in the 2-day-infected NPC cells (Figs. $1 \mathrm{C}$ and 2A). But in the 21-day-infected cells, granular reaction products were markedly decreased (Figs. 1D and 2, B to G). At high magnification, some reaction product was found attached to (Fig. 2C, arrowhead) and riding on (Fig. 2D, arrowhead) the nuclear envelopes, in the cytoplasm (Fig. 2E, arrowheads), and attached to the inner (Fig. 2F, arrowhead) and the outer surfaces of plasma membrane (Fig. 2G, arrowhead). When PCR and Southern blotting were used to identify the EBV DNA in the EBV-infected cells, a marked 110 bp band of EBV in BamHI W fragment was seen in recently infected cells (1-3 weeks), but a weaker band was found after 4 weeks infection (data not shown).

\section{Localization of EBNA-1 Antigen in EBV-Infected NPC Cells}

When antibody against EBNA-1 was used to localize the EBNA-1 in the infected cells, reaction product was not seen in the EBV-free NPC cells (Fig. 3A). But a clear reaction product was found in many nuclei of NPC cells 4 to 5 days after EBV infection (Fig. 3, B and C). In NPC cells 16 days after infection, a strong to moderate EBNA-1 reaction product was seen in only a fraction of NPC cellular nuclei, whereas other cells revealed no immunostaining (Fig. 3D). At 27 days after infection, only focal reaction product could be found in a few infected cell nuclei (Fig. 3, E and F).

For comparison we have localized EBNA-1, LMP-1, EBV-VCA, and IL-6 at the same time (the 10th day after infection). The EBV-infected NPC cells stained with antiEBNA-1 revealed strong reaction product in certain nuclei and moderate in other cells (Fig. 4A). Reaction product of anti-LMP-1 was mainly seen at plasma membrane in many cells with some cells showing weak and no staining (Fig. 4B), whereas reaction product of antiIL-6 was also present in the cytoplasm of many cells, except for a few that were negative (Fig. 4D). No reaction product of anti-EBV-VCA was detected in the EBVinfected cells (Fig. 4C). We also compared the reaction product of anti-IL-6 in EBV-free and EBV-infected cells 10 days after infection. Results showed weak reaction product of anti-IL-6 in the EBV-free cells (data not shown), whereas the EBV-infected cells (10 days after infection) revealed moderate to strong reaction product as shown in Figure 4D.

\section{Identification of mRNA Expression of Growth Factors/Cytokines in EBV-Infected NPC Cells by RT-PCR}

When EBV-infected NPC-TW 01 and 06 cellular RNAs were checked by reverse transcriptase-polymerase chain reaction (RT-PCR) for comparison with their epithelial growth factor receptor (EGFR) mRNA expression at different time periods after infection, it was found that the EGFR mRNA was markedly elevated 2 to 3 weeks after infection (Fig. 5A, lanes 3 and 4), but reduced gradually to its original level 4 weeks after infection (Fig. $5 \mathrm{~A}$, lane 5). When TGF- $\alpha$ was investigated, the mRNA was elevated 1 week after infection (Fig. 5B, lane 2), but it decreased gradually to the original level within 2 to 4 weeks (Fig. 5B, lane 3 to 5). However, the other growth factors, such as TGF- $\beta 1$ (Fig. 5 C), TGF- $\beta$ RI, and TGF$\beta$ RII (data not shown), showed no specific change in their mRNA after EBV infection.

When IL-1 $\beta$ was examined, the result also showed a marked elevation of its mRNA expression 1 week after infection (Fig. 5D, lane 2), but again it decreased to the original level within 2 to 4 weeks after infection (Fig. $5 \mathrm{D}$, lanes 2 to 4). When IL-6 was checked, its mRNA showed marked increase of expression 1 week after infection (Fig. 5E, lane 2) and decreased gradually to the original level within 2 to 4 weeks after infection (Fig. 5E, lanes 3 and 4). A particular finding was seen in granulocyte-macrophage colony-stimulating factor (GM-CSF) expression which showed marked increase of mRNA expression within 2 to 3 weeks after infection (Fig. 5F, lanes 2 and 3). It remained at the increased level with a slightly decreased intensity 4 weeks after infection (Fig. 5F, lane 5). However, the IL-8 and tumor necrosis factor $\alpha$ (TNF- $\alpha$ ) expressions showed no specific change after EBV infection (data not shown). [To confirm the RT-PCR results, we have also performed immunodot methods using serial dilution of 

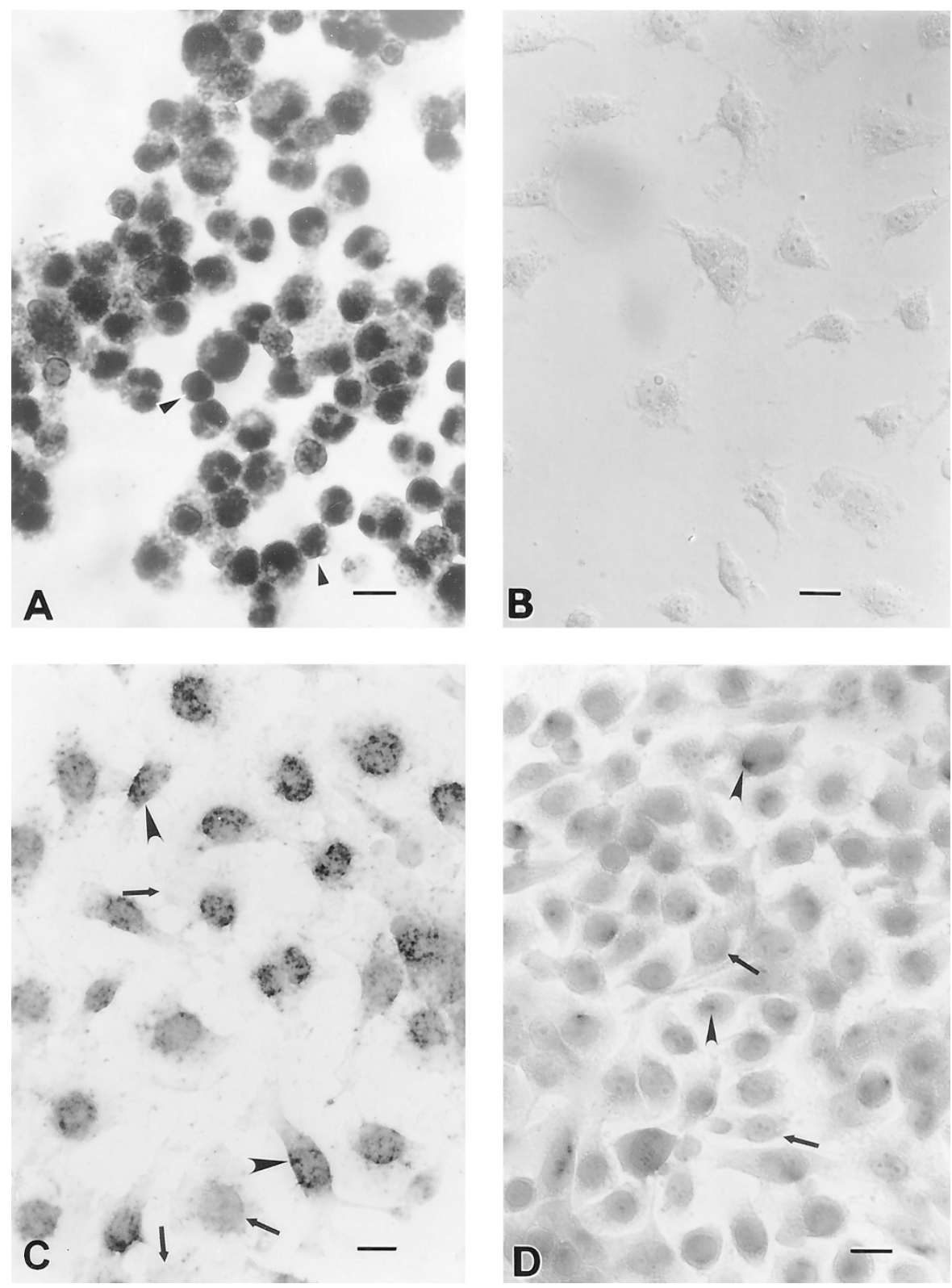

\section{Figure 1.}

Localization of Epstein-Barr virus (EBV) DNA in Raji cells and EBV-infected nasopharyngeal carcinoma (NPC)-TW 01 cells by in situ PCR hybridization. A, Raji cells; B, uninfected NPC cells; C, NPC cells infected by EBV for 2 days; D, cells infected by EBV for 3 weeks. All cells were treated with in situ PCR hybridization to localize EBV DNA. In C, NPC-TW 01 cells show strong multiple granular reaction products (arrowheads) of EBV signal in their nuclei with a few uninfected cells (arrows). But in D, the EBV DNA signal is decreased markedly with some cells containing a few granular reaction products (arrowheads) and many others no reaction products (arrows). The positive control of Raji cells in A reveals strong granular reaction products of EBV signal in each cell, whereas the negative control of uninfected NPC cells in B reveals no EBV signal. (Bars in A-D, $20 \mu \mathrm{m}$.)

supernatants from these cells with antibodies against EGFR and IL-6. The results revealed changes similar to the RT-PCR findings (data not shown).]

In order to confirm that binding of polymeric immunoglobulin IgA to its receptor could not induce cellular gene expression in NPC cells, we treated NPC cells with $\lg A$ anti-EBV-VCA for different time periods and examined the expression of IL- 6 mRNA. Results showed no specific change of IL-6 expression (Fig. 6, lanes 2 to 5) when compared with untreated NPC cells (Fig. 6, lane 1). Similarly, no change of IL-6 expression was found when antibody against SC was applied to
NPC cells, followed by incubation with EBV particles, and then examination of the expression of IL-6 in each incubation time period (data not shown)

The above experiments have all been done in two separate cell lines (NPC-TW01 and NPC-TW-06) with similar results. Therefore, we only showed one representative cell line. (Since the difference between RT-PCR bands of cytokine/growth factor genes and the internal control $\beta$-actin gene were rather clear for comparison in the present experimental conditions, we did not show the densitometric analysis data.) 

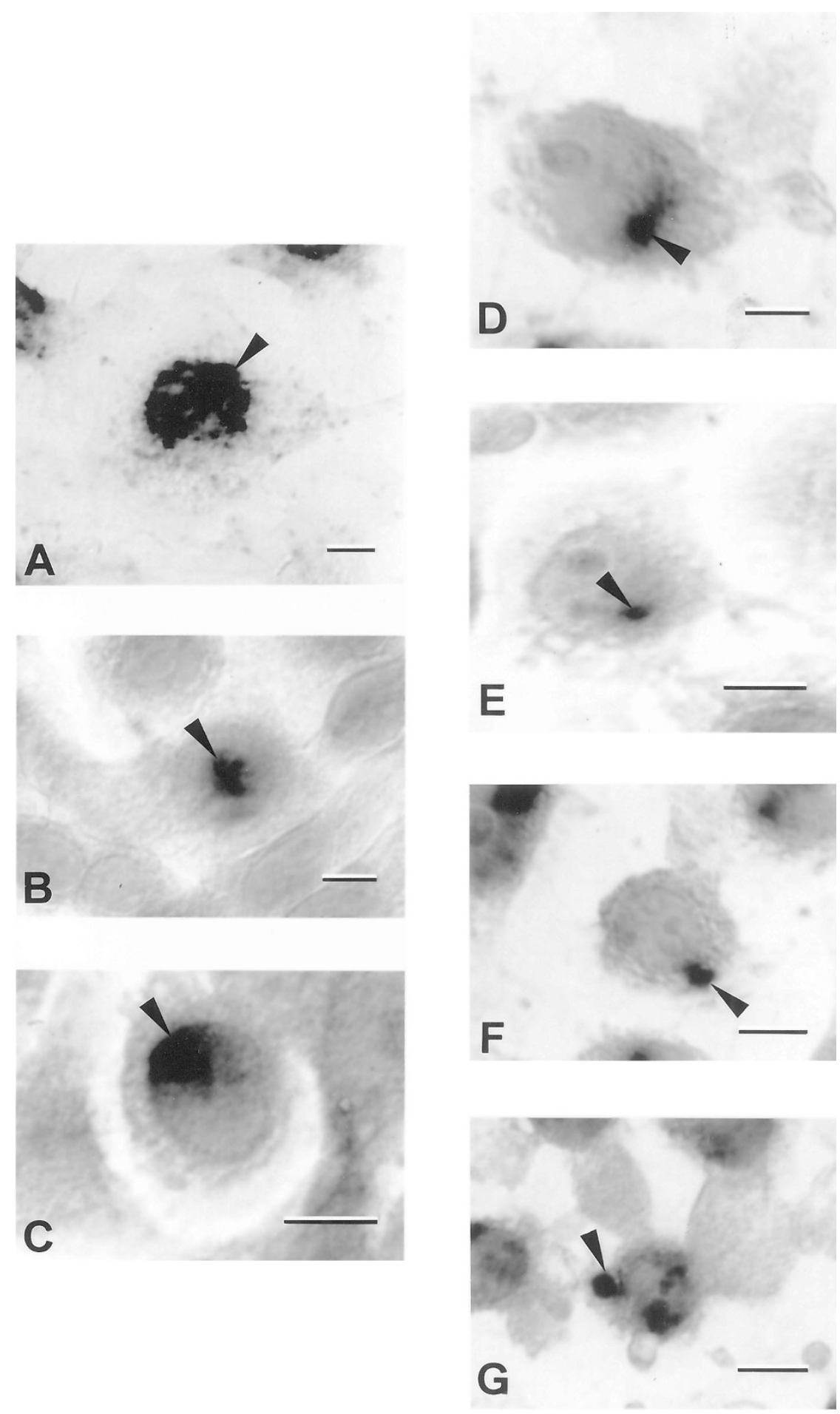

\section{Figure 2.}

A montage of individual NPC cells infected by EBV at high magnification. The experimental condition was the same as in Figure 1. A, NPC-TW 01 cell infected by EBV for 2 days; $B$ to $G$, infected for 21 days. A, Many granular reaction products of EBV DNA signal are aggregated in the nucleus (arrowhead); $B$, a few granules are clustered in the nucleus (arrowhead). The reaction product of EBV signal is attached to the inner surface of the nuclear envelope (arrowhead) in C, overriding on the nuclear envelope (arrowhead) in D, in the cytoplasm (arrowhead) in E, and attached to the inner surface of the plasma membrane (arrowhead) in $\mathrm{F}$. One of the granular reaction products is exocytosed and attached to the external surface of the cell membrane (arrowhead) in G. (Bars in A-C and E-G, $10 \mu \mathrm{m}$; bar in D, $5 \mu \mathrm{m})$.

\section{Discussion}

To ensure that the EBV-infected NPC cell model using polymeric immunoglobulin receptor (plgR)-mediated endocytosis was feasible and reproducible, we incbated NPC cells with NPC patient antiserum and EBV particles and then cultured the cells for different time periods. We identified the EBV DNA in the infected 


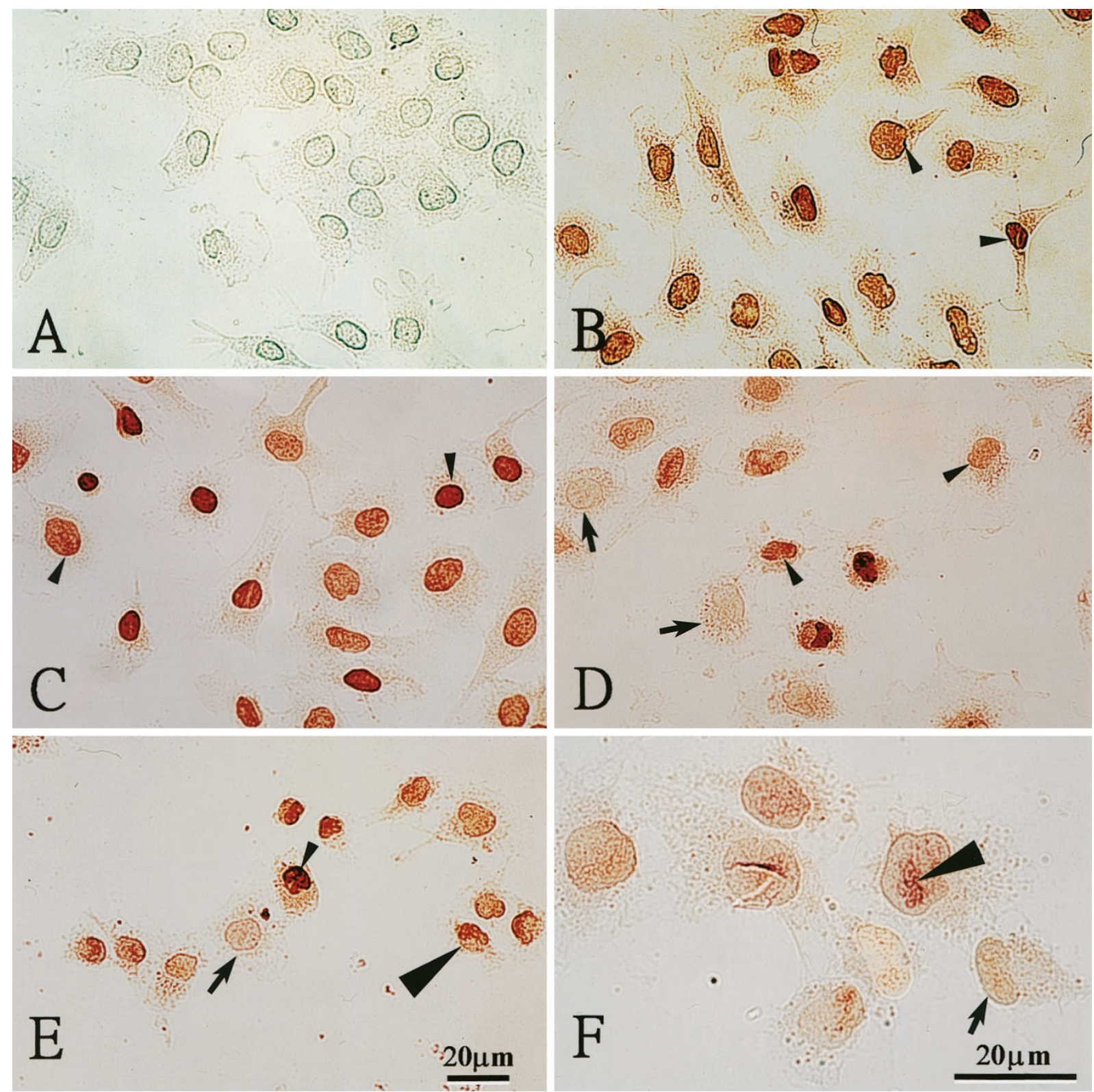

\section{Figure 3.}

Immunohistochemical localization of Epstein-Barr nuclear antigen (EBNA)-1 in EBV-infected NPC-TW 01 cells in vitro. A, The non-EBV-infected NPC cells show no specific reaction product of anti-EBNA-1. B and C, NPC cells infected by EBV for 4 and 5 days, respectively, show clear anti-EBNA-1 reaction product in the nucleus (arrowheads) of each EBV-infected cell. D, NPC cells infected by EBV for 16 days reveal only a fraction of NPC cells containing strong or moderate anti-EBNA-1 reaction product in their nuclei (arrowheads), whereas other cells reveal no immunostaining (arrows). E and F, NPC cells infected by EBV for 27 days. E, only a few cells contain strong reaction product in their nuclei (small arrowhead); a fraction of tumor cells reveal partial immunostaining in the nuclei (large arrowhead). Other cells show no immunostaining (arrow). F, A higher magnification taken from the other area of the 27-day-infected cell population, showing anti-EBNA-1 immunostaining in a small area of one infected nucleus (large arrowhead). Other cells show very little or no immunostaining (arrow).(Bars in A-E, $20 \mu \mathrm{m} ;$ bar in F, $20 \mu \mathrm{m}$.)

cells by in situ PCR hybridization and in the extracted DNA fraction by PCR with Southern blotting. Results showed positive EBV signal in the EBV-infected cells with both methods, a result similar to the previous report (Lin et al, 1997b). In addition, in the in situ PCR hybridization in different incubation time periods, we found a very interesting phenomenon: many granular reaction products of EBV DNA signal were seen in most culture cells (more than 90\%) in NPC cellular nuclei 2 days after infection, but the DNA signal became much weaker (fewer than $50 \%$ of infected cells containing a few granular reaction products) 21 days after infection. Furthermore, in NPC cells with the 21-day-old infection, the granular reaction products of EBV DNA signal were found attached to and overriding the nuclear envelope, distributed in the cytoplasm and attached to the inner surface of the plasma membrane, and exocytosed extracellularly (Figs. 1 and 2). Similarly, PCR with Southern blot analysis revealed that the EBV DNA signal gradually decreased from the earlier infection (2-4 days after infection) to later infection (21-30 days after infection) during the in 


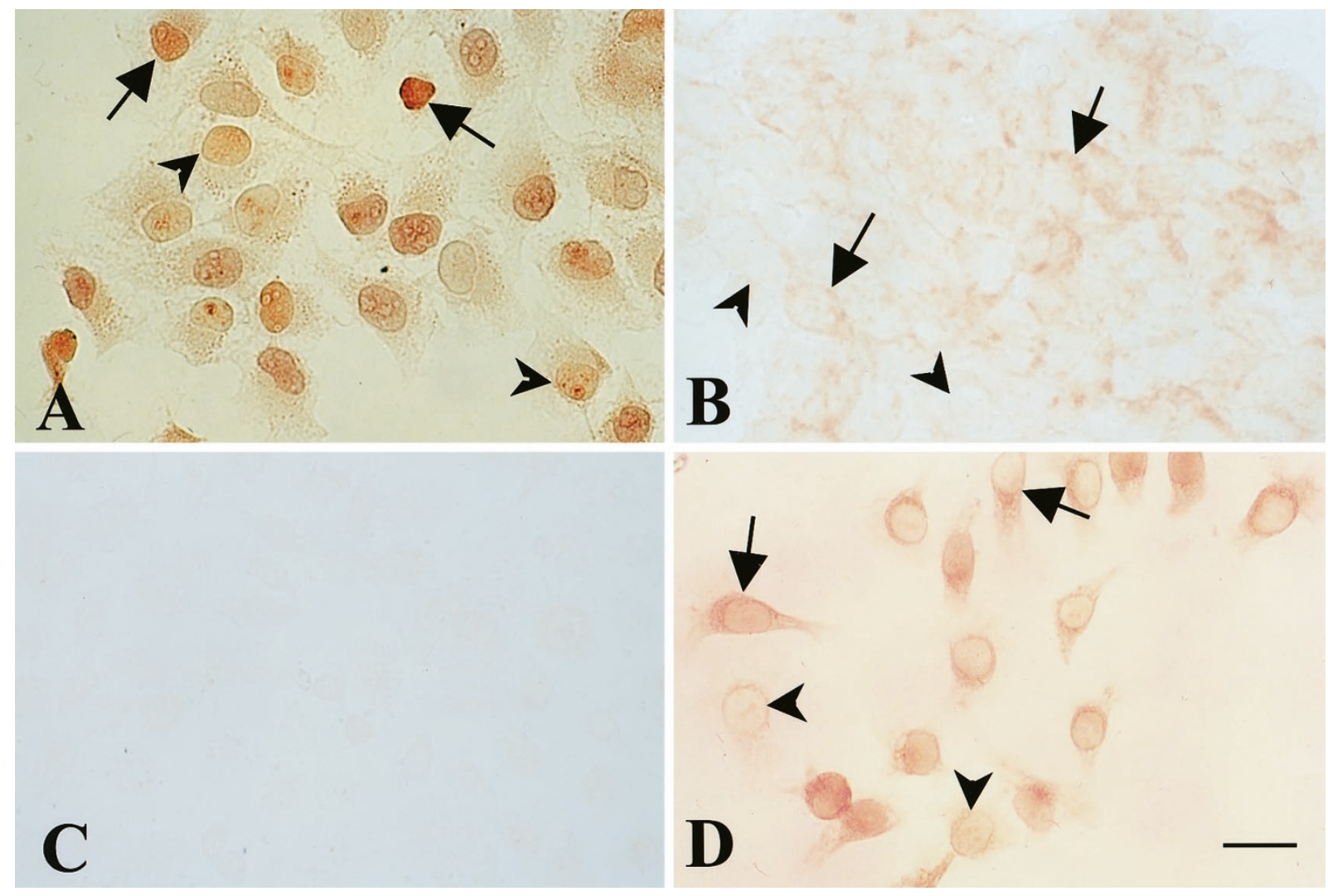

\section{Figure 4.}

Immunolocalization of EBNA-1, latent membrane protein (LMP)-1, interleukin (IL)-6 and EBV-viral capsid antigen (VCA) in NPC-TW 01 cell lines infected by EBV and incubated for 10 days. A, Anti-EBNA-1, shows some cells containing strong nuclear reaction product (arrows) and other cells contain moderate immunostaining (arrowheads); B, anti-LMP-1, shows some cells containing strong membrane staining (arrows) and other cells containing rather weak or no immunostaining (arrowheads); C, anti-EBV-VCA, shows no immunoreactivity; D, anti-IL-6, shows many cells containing strong cytoplasmic immunostaining (arrows) and a few cells containing very weak or no staining (arrowheads). (Bars in A to D, $20 \mu \mathrm{m}$.)

vitro culture passages (data not shown), a change similar to the reversed condition in the early infection periods, from 1 hour to 24 hours after infection, in which the EBV signal gradually increased (Lin et al, 1997b). We have observed that a trace of EBV DNA and EBNA-1 persisted in the infected cultures for 2 months. However, after 70 days, all EBV genome had disappeared. These findings were also similar to our previously published data that EBV DNA was discharged gradually in the EBV-positive cell lines during serial passages (Lin et al, 1994). [Our unpublished data, using CaSki cells (a uterine cervical cancer cell line with positive SC protein expression) infected by EBV through the same EBV-IgA-SC complex, also showed the discharge of EBV genome after 1 to 2 months infection. But when we infected the HeLa cells (another uterine cervical cancer cell line without SC protein expression) with EBV, no EBV genome could be detected in the HeLa cells]. Although the experimental results are snapshots, both experiments do suggest that during cell passage the EBV episomes gradually moved from the nucleus into the cytoplasm and were finally exocytosed extracellularly.

The reason(s) for the exocytosis of EBV episomes during the in vitro passages is not clear. Since EBNA-1 protein expression has been identified in all EBVinfected cells, this protein may play some role in maintenance of EBV episomes in the infected cells (Nemerow and Cooper, 1981; Pearson, 1993). Therefore, we have used antibody anti-EBNA-1 to stain the EBV-infected NPC cells in different time periods. Results showed a similar finding that in the EBV-free NPC cells no EBNA-1 protein could be detected, but it appeared in the cells infected with EBV after approximately 1 to 2 weeks, and it decreased gradually during the 3rd and 4th week (Fig. 3). Apparently, the appearance and disappearance of EBNA-1 protein in the EBV-positive and EBV-negative cells are in parallel with each other. This finding supports the hypothesis that EBNA-1 may be required for maintenance of EBV episomes in the infected cells (Nemerow and Cooper, 1981; Pearson, 1993). It also suggests that in the in vitro EBV-infected cells, EBNA-1 expression may be suppressed by some unknown cellular factor(s) during the cellular passage resulting in discharge of EBV plasmids from the cells. Another possible explanation for this phenomenon is that EBV plasmids in the nuclei of in vitro cultured cells may require some unknown specific factors for maintenance of the plasmids inside the infected cells and these factors are missing in our culture medium, unlike the in vivo microenvironment which contains certain specific factors to keep the EBV plasmids in the in vivo EBV-infected tumor cells, such as in the EBV-positive NPC cells in the biopsy 


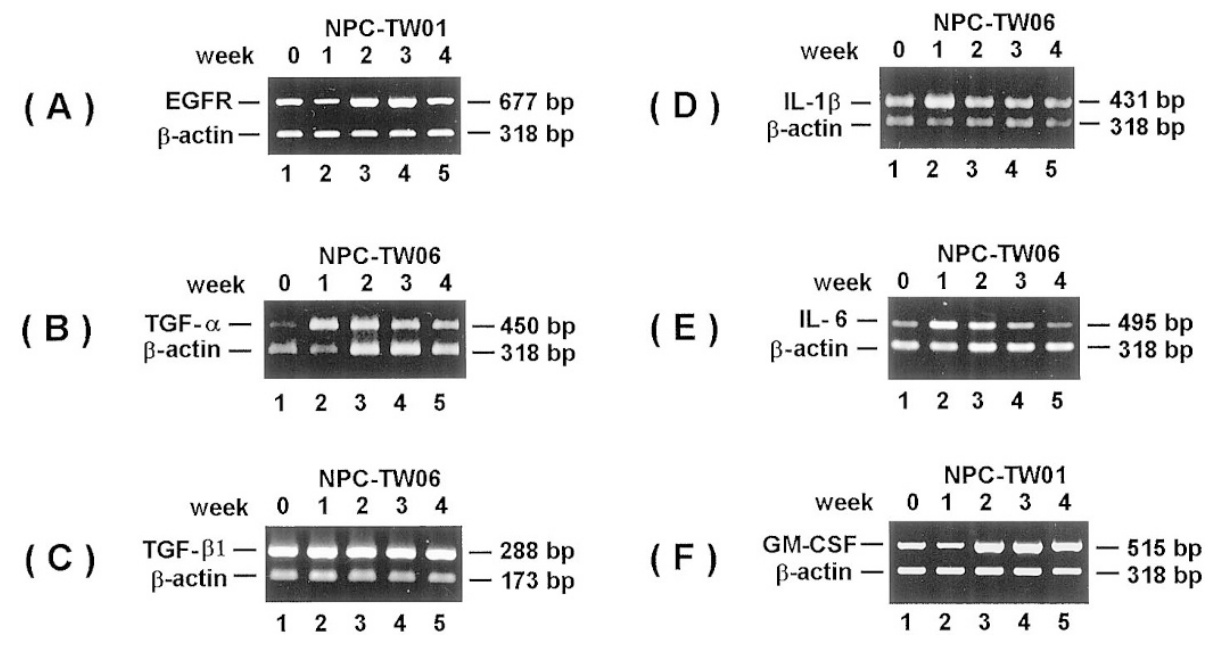

\section{Figure 5.}

RT-PCR analysis of growth factor and cytokine expression in NPC-TW 01 and NPC-TW 06 cell lines after EBV infection for 1, 2, 3, and 4 weeks, respectively. A, The gel analysis of RT-PCR product of EGFR-mRNA in NPC-TW 01 cell line. After EBV infection for 2-3 weeks, the EGFR mRNA of 677 band shows markedly increased intensity (lanes 3,4$)$. But 4 weeks after infection, the intensity of this band is decreased to the original level (lane 5 ). The internal control $\beta$-actin band has 318 bp. B, RT-PCR analysis of TGF- $\alpha$ mRNA expression in NPC-TW 06 cell line. After infection for 1 week, the TGF- $\alpha$ mRNA of 450 bp band is markedly elevated (lane 2), but gradually returns to the original level between $2-4$ weeks after infection (lanes $3,4,5$ ). The $\beta$-actin band of $318 \mathrm{bp}$ is an internal control band. C, RT-PCR analysis of TGF- $\beta 1$ mRNA expression in NPC-TW 06 cell line. The TGF- $\beta 1$ mRNA expression of 288 bp band shows no specific change after EBV infections (lanes 2-5). The $\beta$-actin band of $173 \mathrm{bp}$ is the internal control. D, RT-PCR analysis of IL-1 $\beta$ mRNA expression in NPC-TW 06 cell line. The intensity of 431 bp band of IL- $1 \beta$ mRNA is increased 1 week after EBV infection (lane 2), but gradually recovered to the original level 2, 3, and 4 weeks after infection (lanes $3,4,5$ ). The 318 bp band of $\beta$-actin mRNA is an internal control. E, RT-PCR analysis of IL-6 mRNA expression in NPC-TW 06 cell line. The intensity of 495 bp band of IL-6 mRNA is increased after EBV infection for 1 week (lane 2). But it decreases gradually to the original level 2-4 weeks after infection (lanes 3, 4, and 5). The 318 bp band of $\beta$-actin mRNA is an internal control. F, RT-PCR analysis of granulocyte-macrophage colony-stimulating factor (GM-CSF) mRNA expression in NPC-TW 01 cell line. The intensity of $515 \mathrm{bp}$ band of GM-CSF product is markedly increased 2-3 weeks after infection (lanes 2 and 3). It maintains the increased level, with slightly decreased intensity, 4 weeks after infection (lane 5). The $318 \mathrm{bp}$ band of $\beta$-actin product is an internal control. Each experiment has been repeated 3 times.

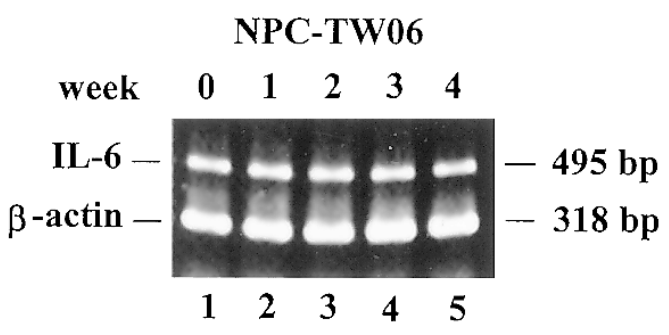

Figure 6.

RT-PCR analysis of IL-6 expression in NPC cells treated with immunoglobulin A (IgA) anti-EBV-VCA only for 1, 2, 3, and 4 weeks. The PCR reaction product of IL-6 mRNA expression in the NPC-TW 06 cell was analyzed in the gel electrophoresis. The same intensity of 495 bp band of IL-6 mRNA expression is seen in each lane. Lane 1, Untreated NPC cells; lanes 2 to 5 , NPC cells treated with IgA anti-EBV-VCA and incubated from 1 to 4 weeks, respectively. The $318 \mathrm{bp}$ band of $\beta$-actin mRNA is the internal control.

specimens. (The EBNA-2 protein expression was not examined in the present experiment).

For comparison of the expression of endogenous and exogenous gene product in EBV-infected NPC cells, we used antibodies against EBNA-1, LMP-1, EBV-VCA, and IL-6 to observe their protein expressions at the same time after infection (ie, at the 10th day after infection). It was clear that no EBV-VCA was expressed, but EBNA-1, LMP-1 and IL-6 proteins were expressed after EBV infection. These findings indicate that NPC cells after EBV infection not only express viral protein, such as EBNA-1 and LMP-1, but also express host cellular protein (IL-6). We have also used antibody against IL-6 to stain the non-EBV- infected NPC cells and found that the latter contained rather weak reaction product of anti-IL-6 when compared with the EBV-infected cells (data not shown). These findings indicate that EBV infection can upregulate IL-6 protein expression. Furthermore, when we performed in situ hybridization to localize EpsteinBarr viral encoded RNA (EBER)-1, we could demonstrate a positive signal in certain EBV-positive cells 18 days after infection (Lin C-T, Kao H-J, Lin J-L, Chan W-Y, Wu H-C, and Liang S-T, unpublished data). All of these results suggest that the viral genomes in the host cells are in a latent phase.

Using this infection method, we incubated the EBVinfected NPC cells for 1, 2, 3, and 4 weeks. Their total RNAs were extracted for semiquantitative RT-PCR analysis of different mRNA expression. We selected certain growth factors, such as EGFR, $\operatorname{TGF} \alpha, \operatorname{TGF} \beta 1$, TGF $\beta$ RI, TGF $\beta$ RII, and cytokines, such as IL-1 $\beta$, IL-6, $\mathrm{TNF} \alpha$, GM-CSF, for this experiment, firstly, because we wanted to know why the EBV-infected tumor cells showed a clonal expansion in vivo, (Lin et al, 1994) (a suggestion of faster proliferation). Therefore, we selected the growth factors which are more common for epithelial cell proliferation. Secondly, we are interested in the phenomenon that $\lg \mathrm{A}$ antibody titer against EBV-VCA is always elevated or decreased and is followed by tumor proliferation or decreased tumor size after radiotherapy. For this reason we have chosen the cytokines that are more associated with antibody production. (In our unpublished data we have also included other cytokines, such as IL-4, IL-8, and 
IL-10, for the studies, and all of them showed no specific change). The fact that the expression of EGFR mRNA increased in the 2 to 3 weeks after EBV infection and then gradually decreased to the original level by 4 weeks after infection indicates that EBV infection activates the host cellular EGFR expression, which may result in an increase in the rate of cellular proliferation through a paracrine or autocrine pathway (Boonstra et al, 1995; Santini et al, 1991; Zheng et al, 1994).

A similar result has been reported by Miller et al (1995). In this report, the LMP-1 gene was transfected to a uterine cervical carcinoma cell line that showed increased EGFR expression. We propose that the elevation of EGFR expression in our EBV-infected NPC cells may be due to the effect of LMP-1 protein and other unidentified proteins produced by EBV. A similar effect of EBV infection on TGF- $\alpha$ expression was also found, but here we could identify the marked elevation of TGF- $\alpha$ mRNA expression in the infected cell line 1 week after infection. We believe that the elevation of TGF- $\alpha$ expression in EBV-infected cells may also play some role in the progression of NPC cell growth (Arai et al, 1990; Derynck, 1992; Kumar et al, 1995; Untawale et al, 1993), similar to the effect of EGFR. However, it should be pointed out that the elevation of EGFR and TGF- $\alpha$ expressions after EBV infection seems to be a temporary phenomenon, probably caused by the decrease of EBV genomes in the infected cells during the in vitro passages. The findings that the expression of TGF- $\beta 1, T G F-\beta R I$, and TGF- $\beta$ RII in EBV-infected NPC cells in the present experiment showed no specific change suggest that EBV infection has no relationship to the expression of TGF- $\beta$ and its receptors.

For IL-1 $\beta$ expression in the EBV-infected cells, our results showed marked elevation of IL-1 $\beta$ expression 1 week after infection. But again it decreased to the control level 2 weeks after infection. It has been proposed that IL-1 $\beta$ works in combination with IL- 6 to activate $\mathrm{T}$ helper cells and natural killer cells and promote $B$ cell maturation and clonal expansion (Bende et al, 1992; Collard and Gearing, 1994). If so, the elevation of IL-1 $\beta$ expression in EBV-infected NPC cells may enhance the host immune system to reduce NPC progression. Increased synthesis of cytokine IL-6 from certain tumor cells has been previously reported (Bende et al, 1992; Clemens, 1991; Kuby, 1992; Nicola, 1994). Results from our EBV-infected NPC cells also revealed marked increase of IL-6 mRNA expression 1 to 2 weeks after infection, indicating that EBV infection in NPC cells could enhance IL-6 mRNA expression. This finding is supported by the immunohistochemical result that IL-6 protein expression is up-regulated by EBV infection as mentioned above. The important functions of IL- 6 are to stimulate B cells to produce more $\lg G$ and $\lg A$ (Tanner and Menezes 1994) and to convert the latent phase of EBV genome in EBV-infected B cells into a lytic phase of EBV replication in the infected cells (Tanner and Menezes 1994). Consequently, it is reasonable to predict that the increase of IL-6 synthesis from EBV-infected NPC cells may cause the tumor-infiltrating, EBV-primed, B lymphocytes to synthesize more $\operatorname{lgG}$ and $\lg A$ anti-EBV protein. Furthermore, IL-6 synthesis may also cause the tumor-infiltrating, latently EBV-infected, B lymphocytes to become B cells containing a lytic phase of EBV replication. However, further experiments are needed to confirm this speculation.

Although up-regulation of host cytokine/growth factor gene expressions by EBV infection can be observed as demonstrated in the present experiment, the possibility that it may be induced by the process of endocytosis via the $\lg \mathrm{A}$ receptor cannot be totally ruled out. Therefore, we have performed an experiment to observe this possibility. The fact that NPC cells, when treated with IgA anti-EBV only and incubated for different time periods, showed no specific change of IL-6 mRNA expression (Fig. 6), strongly indicates that binding of $\lg A$ to its receptor on NPC cells does not induce cytokine gene expression in the host cells.

The data for IL-8 and TNF- $\alpha$ expression showed no specific change after EBV infection, indicating that IL-8 and TNF- $\alpha$ are not regulated by EBV product. However, when GM-CSF was examined, a clear elevation of its mRNA was found in the 2nd and 3rd weeks after infection, and it remained at the elevated level, with slightly decreased intensity, 4 weeks after infection. The function of GM-CSF is to stimulate bone marrow stem cells to proliferate more granulocytes and monocytes for protection and enhancement of the host defense system (Bende et al, 1992; Clemens, 1991; Kuby, 1992; Nicola, 1994). It is not clear whether it has specific relationship with tumor progression.

In summary, in EBV-infected NPC cells in vitro, we have demonstrated that the EBV genome could transcribe EBER-1 and express EBNA-1, LMP-1 but not EBV-VCA. The infected virus particles were discarded from NPC cells by a cellular exocytosis process after long-term and serial passages, probably because of the suppression of EBNA-1 expression in the infected cells by some unidentified factors or some unknown factors in the in vivo microenvironment that are missing in the in vitro culture medium. Also, we have demonstrated that EBV protein products could cause elevation of gene expressions of some growth factors, such as EGFR and TGF- $\alpha$, and of some cytokines, such as IL-1 $\beta$, IL-6, and GM-CSF. However, some growth factors, such as TGF- $\beta 1$, TGF- $\beta$ RI, and TGF$\beta$ RII, and some cytokines, such as IL- 8 and TNF- $\alpha$, were not affected by EBV infection. When EBV particles were discharged from the infected cells, the change in gene expressions subsided. It is concluded that NPC cells proliferate faster than EBV-negative cells, probably through the activation of cellular gene expression of growth factors and cytokines. However, in vitro, these EBV-infected NPC cells rid themselves of EBV genomes by exocytosis, probably through the sort of unidentified cellular factors that are necessary to maintain the viral genome in the host cells. 


\section{Materials and Methods}

\section{Cell Lines and Culture}

Two representative NPC cell lines [NPC-TW 01-50 (NPC-TW 01 at 50th passage) and NPC-TW 06-50] were used for this experiment. NPC-TW 01 was derived from a keratinizing squamous cell carcinoma (WHO Type I) (Lin et al, 1990), and NPC-TW 06 from an undifferentiated carcinoma (WHO Type II b) (Lin et al, 1993). Although both lines contained EBV DNA at early passages, both became negative after 30 passages (Lin et al, 1994). Both cell lines were cultured in DMEM containing 5\% FCS and incubated in a $10 \% \mathrm{CO}_{2}$ incubator. Another two cell lines, B95-8 line (a marmoset lymphoblastoid line containing both latent and lytic forms of EBV) and the Raji cell line (derived from a B cell Burkitt's lymphoma) were used for isolation of EBV particles and to serve as controls.

\section{Preparation of EB Viral Particles}

The procedures used for isolation of EBV particles and identification of viral DNA in the isolated solution were modified from a previously published method (Ausubel et al, 1990; Lin et al, 1997b). Briefly, B95-8 cells were cultured and mixed with 12-Otetradecanoylphorbol-13-acetate (TPA) $(20 \mathrm{ng} / \mathrm{ml})$ and then reincubated for approximately 7 to 14 days. The cells and culture medium were centrifuged at 1,500 $\times g$ for 30 minutes. The supernatant was then added mixed with bacitracin at a final concentration of 100 $\mu \mathrm{g} / \mathrm{ml}$, and filtrated using a filter with $0.8-\mu \mathrm{m}$ pore size. The supernatant was recentrifuged at $15,000 \times g$ for 2 hours. The precipitate was then dissolved in $1 \%$ of the original volume of culture medium. The viral solution was subjected to PCR analysis of EBV DNA using primers according to our previously published paper (Lin et al, 1994) and showed positive EBV DNA (data not shown). It was aliquoted and stored at $-79^{\circ} \mathrm{C}$ for future use. For all of the following experiments, we did not perform the experiments using inactivated virus, because it was not the purpose of this study.

\section{Procedure for EBV Infection}

The procedure for EBV infection was performed according to the previously published method using EBV-IgA-SC-mediated endocytosis with some modification (Lin et al, 1997b; Sixbey and Yao, 1992). Briefly, two NPC cell lines (NPC-TW01 and NPCTW06) were cultured overnight, washed twice with serum-free DMEM, and incubated with the NPC patient's serum diluted at 1:50 with DMEM, respectively. The patient's serum contained high titer of IgA antiEBV-VCA (1:640) and could neutralize EBV with regard to the infection of $B$ cells. The cells were incubated at $4^{\circ} \mathrm{C}$ for 30 minutes, rinsed with cold DMEM twice, added to a crude EBV preparation, and then incubated for another 30 minutes at $4^{\circ} \mathrm{C}$. They were then incubated at $37^{\circ} \mathrm{C}$ for $1,2,3$, and 4 weeks. The cells were then collected and used for the experiments described below. In the control cases, some cells were treated either with human IgA anti-EBV VCA only (without addition of EBV), or with antibody against SC (Sigma, St. Louis, Missouri) for 30 minutes, and then subjected to EBV infection as mentioned above. Both conditions were then analyzed by RT-PCR for assay of IL-6 mRNA expression.

\section{In Situ PCR Hybridization and PCR-Southern Blotting}

To confirm successful EBV infection in NPC cells, in situ PCR hybridization and PCR-Southern blotting were performed. After infection by EBV, the NPC cells were cultured on the coverslips for different time periods and then fixed for in situ PCR hybridization according to our previously published method with some modification (Lin et al, 1994). Briefly, the cells on coverslips after fixation in 3\% paraformaldehyde and washing, were treated with PCR buffer containing primers derived from an EBV-BamHI W fragment (Lin et al, 1994) and sealed with rubber cement and subjected to the PCR program. The coverslips were then washed and hybridized with digoxigenin (dig)labeled EBV probe and incubated with alkaline phosphatase (AP)-labeled antibody against dig and with AP substrate. For negative control, the NPC cells were treated with the antibody against SC before being incubated with EBV and then subjected to in situ PCR hybridization. Some EBV-infected cells were tested using PCR-Southern blot analysis to identify EBV DNA (Lin et al, 1994). Briefly, DNA was isolated from EBV-infected NPC cells with different infection periods by SDS lysis, proteinase K digestion, and phenol/ chloroform extraction. One $\mu \mathrm{g}$ of DNA from each condition was subjected to PCR amplification and transferred to a nylon membrane and hybridized with dig-labeled EBV probe.

\section{Immunolocalization of EBNA-1, LMP-1, EBV-VCA, and IL-6 in EBV-Infected NPC Cells}

For localization of EBNA-1 protein expression in EBVinfected NPC cells, a routine immunohistochemical method previously developed by our laboratory was used (Lin et al, 1997b). Briefly, after incubation for 1, 3, and 4 weeks, EBV-infected NPC cells were fixed for immunostaining using antibody against EBNA-1 (Calbiochem, San Diego, California) with 1:50 dilution. For comparison of protein expression from endogenous and exogenous gene transcripts in the EBV-infected NPC cells, we localized EBNA-1, EBV-VCA, LMP-1, and IL-6 proteins at the same time, 10 days after EBV infection.

\section{Reverse Transcriptase (RT)-PCR Analysis of Cellular RNA Expression}

To analyze the change in growth factor and cytokine gene expression after EBV infection, we used a semiquantitative RT-PCR to observe cellular mRNA expression (Wilkinson, 1988). The RNAs were isolated from the uninfected and EBV-infected NPC cell lines, which had been incubated for 1, 2, 3, and 4 weeks, by NP-40-sodium deoxycholate dextran sulfate lysis and phenol/chloroform/amylalcohol extraction (Wang et al, 
Table 1. Primers for Polymerase Chain Reaction

\begin{tabular}{|c|c|c|c|c|}
\hline Primers & Sequence & Base & $\begin{array}{l}\mathrm{MgCl}_{2} \\
(\mathrm{mM})\end{array}$ & Reference \\
\hline$\beta$-actin & $\begin{array}{l}\text { 5'-ATCATGTTTGAGACCTTCAA-3' } \\
\text { 5'-CATCTCTTGCTCGAAGTCCA-3' }\end{array}$ & $318 b p$ & $1.5-2.0$ & Jindal et al, 1995 \\
\hline$\beta$-actin & $\begin{array}{l}\text { 5'-CGGGAAATCGTGCGTGACAT-3' } \\
\text { 5'-GAAGGAAGGCTGGAAGAGTG-3' }\end{array}$ & $173 b p$ & $1.5-2.0$ & Jindal et al, 1995 \\
\hline EGF receptor & $\begin{array}{l}\text { 5'-CTCATTGCCCTCAACACAGT-3' } \\
\text { 5'-CGTCTTCCTCCATCTCATAG-3' }\end{array}$ & $677 b p$ & 1.5 & Jindal et al, 1995 \\
\hline TGF $\alpha$ & $\begin{array}{l}\text { 5'-TTCGCTCTGGGTATTGTGTT-3' } \\
\text { 5'-CTCCTCCTCTGGGCTCTTCA-3' }\end{array}$ & $450 \mathrm{bp}$ & 1.5 & Nishida et al, 1995 \\
\hline TGF- $\beta 1$ & $\begin{array}{l}\text { 5'-CTCCGAGAAGCGGTACCTGAAC-3' } \\
5^{\prime} \text {-CACTTGCAGTGTGTTATCCCT-3' }\end{array}$ & $288 b p$ & 1.5 & Nishida et al, 1995 \\
\hline TGF- $\beta$ receptor I & $\begin{array}{l}\text { 5'-TGAGAAAAGTTGTTTGTGAAC-3' } \\
5^{\prime} \text {-TGACTGAGTTGCGATAATGT-3' }\end{array}$ & $160 \mathrm{bp}$ & 1.5 & Nishida et al, 1995 \\
\hline TGF- $\beta$ receptor II & $\begin{array}{l}\text { 5'-AGGGACCTCAAGAGCTCCAATAT-3' } \\
\text { 5'-ATCCTGGATTCTAGGACTTCTGG-3' }\end{array}$ & $169 b p$ & 1.5 & Jindal et al, 1995 \\
\hline IL-1 $\beta$ & $\begin{array}{l}\text { 5'-CGATCACTGAACTGCACGCTCCG-3' } \\
\text { 5'-GGTGAAGTCAGTTATATCCTGGCCG-3' }\end{array}$ & $431 b p$ & 1.5 & Auron et al, 1984 \\
\hline IL-6 & $\begin{array}{l}\text { 5'-CACACAGACAGCCACTCACCTC-3' } \\
\text { 5'-CTCAGGGTGGACTGCAGGAAC-3' }\end{array}$ & $495 b p$ & 1.5 & Hirano et al, 1986 \\
\hline IL-8 & $\begin{array}{l}\text { 5'-GCAGCTCTGTGTGAAGGTGCAG-3' } \\
\text { 5'-GCATCTGGCAACCCTACAACAG-3' }\end{array}$ & $365 b p$ & 1.5 & Thalmeier et al, 1996 \\
\hline TNF- $\alpha$ & $\begin{array}{l}\text { 5'-CTTCTGCCTGCTGCACTTTGGA-3' } \\
\text { 5'-TCCCAAAGTAGACCTGCCCAGA-3' }\end{array}$ & $547 b p$ & 1.5 & Mahe et al, 1992 \\
\hline GM-CSF & $\begin{array}{l}\text { 5'-ATGTGAATGCCATCCAGGAGGC-3' } \\
\text { 5'-CCCATTCTTCTGCCATGCCTGT-3' }\end{array}$ & $515 b p$ & 1.5 & King et al, 1995 \\
\hline EBV-Bam HI W & $\begin{array}{l}\text { 5'-GTTCGCGTTGCTAGGCCACC-3' } \\
\text { 5'-AGGACCACTTTATACCAGGG-3' }\end{array}$ & $110 \mathrm{bp}$ & 2.5 & Lin et al, 1994 \\
\hline
\end{tabular}

1989). For synthesis of cDNA, $2 \mu \mathrm{g}$ of total RNA from each condition was mixed with $0.5 \mu \mathrm{g}$ oilgo dT 15 meres and distilled water to make a final volume of 30 $\mu \mathrm{l}$ in toto, incubated at $75^{\circ} \mathrm{C}$ for 5 minutes, and then shifted to $4^{\circ} \mathrm{C}$. This final volume was mixed with 10 $\mu$ l of M-MLV RT buffer (250 mM DTT, $187.5 \mathrm{mM} \mathrm{KCl}$, $1250 \mathrm{mM}$ Tris- $\mathrm{HCl}, \mathrm{pH} 8.3$, at $\left.37^{\circ} \mathrm{C}\right), 8 \mu \mathrm{l}$ of $2.5 \mathrm{mM}$ dNTPs, $39 \mathrm{U}$ rRNAsin (Promega, Madison, Wisconsin), and $200 \cup \mathrm{M}-\mathrm{MLV}$ RNase $\mathrm{H}$ minus reverse transcriptase (Promega), to a total volume of $50 \mu \mathrm{l}$, mixed well, and then incubated at $42^{\circ} \mathrm{C}$ for 2 hours. The reaction was stopped by incubating at $95^{\circ} \mathrm{C}$ for 5 minutes. After dilution, the reaction product was aliquoted and the RT product was stored at $-79^{\circ} \mathrm{C}$ until used.

For $\mathrm{RT}-\mathrm{PCR}$, the $\mathrm{RT}$ reaction product (containing approximately $0.005-0.02 \mu \mathrm{g}$ of original RNA) was added to PCR buffer, $0.5 \mu \mathrm{M}$ of each mRNA primer (the primer sequence for each mRNA is shown in Table 1), $0.25 \mu \mathrm{M}$ of $\beta$-actin primers [for internal control as suggested (Massague, 1990; Paludan and Thestrup-Pedersen, 1992)], and approximately 1.5 to $2.0 \mathrm{mM} \mathrm{MgCl}_{2}, 2 \cup$ Taq polymerase (Promega) to a final volume of $25 \mu$ l. For PCR we used a touch-down program (Carpenter, 1987), ie, the annealing temperature was gradually decreased every two cycles. The first cycle for this reaction program started at $95^{\circ} \mathrm{C}$ for 3 minutes, then $65^{\circ} \mathrm{C}$ for 1 minute, and $72^{\circ} \mathrm{C}$ for 1 minute. For the second and third cycles, the condition was the same: $95^{\circ} \mathrm{C}$ for 30 seconds, then $64^{\circ} \mathrm{C}$ for 1 minute, and $72^{\circ} \mathrm{C}$ for 1 minute. Thereafter, the annealing temperature was decreased $1^{\circ} \mathrm{C}$ every two cycles, from $64^{\circ} \mathrm{C}$, until it reached $56^{\circ} \mathrm{C}$. The final cycle went to $95^{\circ} \mathrm{C}$ for 30 seconds, then $55^{\circ} \mathrm{C}$ for 1 minute, and $72^{\circ} \mathrm{C}$ for 1 minute. Finally, it was stopped at $72^{\circ} \mathrm{C}$ and then kept at $4^{\circ} \mathrm{C}$. The PCR product was checked by $2 \%$ agarose gel electrophoresis in Tris base-boric acid-EDTA buffer.

\section{Acknowledgements}

We thank Dr. June Lin for her critical review of this manuscript.

\section{References}

Ablashi DV, Huang AT, Pagno JS, Peasson GR, and Yang CS (1991). Epstein-Barr virus and human disease, 1990. Clifton, New Jersey: Humana Press, 313-338, 385-390.

Arai KI, Lee F, Miyajima A, Miyatake S, Arai N, and Yokota T (1990). Cytokines: Coordinators of immune and inflammatory responses. Annu Rev Biochem 59:783-836.

Armstrong RW, Armstrong MJ, Yu CM, and Henderson BE (1983). Salted fish and inhalants as risk factor for nasopharyngeal carcinoma in Malaysian Chinese. Cancer Res 13: 2967-2970.

Auron PE, Webb AC, Rosenwasser LJ, Mucci SF, Rich A, Wolff SM, and Dinarello CA (1984). Nucleotide sequence of human monocyte interleukin 1 precursor cDNA. Proc Natl Sci U S A 81:7907-7911. 
Ausubel FM, Brent R, Kingston RE, Moore DD, Seidman JG, Smith JA, and Struhl K, editors (1990). Current Protocols in Molecular Biology, vol 3. New York: Green Publishing Associates and Wiley-Interscience, ch 15.

Bende RJ, Jochems GJ, Frame TH, Klein MR, van Eijk RV, van Lier RA, and Zeijlemaker WP (1992). Effects of IL-4, IL-5, and IL-6 on growth and immunoglobulin production of Epstein-Barr virus-infected human B cells. Cell Immunol 143:310-323.

Boonstra J, Rijken P, Humbel B, Cremers f, Verkleij A, and Henegouwen PB (1995). The epidermal growth factor. Cell Biol Int 19:413-430.

Carpenter G (1987). Receptors for epidermal growth factor and other polypeptide mitogens. Annu Rev Biochem 59:881914.

Chan S (1990). Aeitology of nasopharygeal carcinoma. Ann Acad Med Singapore 19:201-207.

Collard RE and Gearing AJH (1994). The cytokine facts book. London: Academic Press, 2-143.

Derynck R (1992). The physiology of transforming growth factor- $\alpha$. Adv Cancer Res 58:27-52.

de The $G$ (1982). Epidemiology of the Epstein-Barr virus and associated diseases. In: Roizman B (ed). The herpes viruses. New York: Plenum Press, 25-103.

Hirano T, Yasukawa K, Harada H, Taga T, Watanabe Y, Matsuda T, Kashiwamura S-I, Nakajima K, Koyama K, Iwamatsu A, Tsunasawa S, Sakiyama F, Matsui H, Takahara Y, Tanihuchi T, Kishimoto T (1986). Complementary DNA for a novel human interleukin (BSF-2) that induces $B$ lymphocytes to produce immunoglobulin. Nature 324:7376.

Hirayama $T$ and Ito $Y$ (1981). A new view of the etiology of nasopharyngeal carcinoma. Prev Med 10:614-622.

Ho CK, Lo WCH, Huang PH, Wu MT, Christiani DC, and Lin CT (1999). Suspected nasopharyngeal carcinoma in three workers with long-term exposure to sulfuric acid vapor. Occup Environ Med 56:426-428.

Jindal SK, Ishii E, Letaret M, Vera S, Teerds KJ, and Dorrington JH (1995). Regulation of transforming growth factoragene expression in an ovarian surface epithelial cell line derived from a human carcinoma. Biol Reprod 52:10271037.

King A, Jokhi PP, Smith SK, Sharkey AM, and Loke YW (1995). Screening for cytokine mRNA in human villous and extravillous trophoblasts using the reverse-transcriptase polymerase chain reaction (RT-PCR). Cytokine 7:364-371.

Klein G, Giovanella BC, Lindahl T, Fialkow RJ, Singh S, and Stehlin JS (1974). Direct evidence for the presence of Epstein-Barr virus DNA and nuclear antigen in malignant epithelial cells from patients with poorly differentiated carcinoma of the nasopharynx. Proc Natl Acad Sci U S A 71:4737-4741.

Kumar V, Bustin SA, and McKay IA (1995). Transforming growth factor alpha. Cell Biol Int 19:373-388.

Lin CT, Chan WY, Chen W, Huang HM, Wu HC, Hsu MM, Chuang SM, and Wang CC (1993). Characterization of seven newly established nasopharyngeal carcinoma cell lines. Lab Invest 68:716-727.
Lin CT, Chen WS, Hsu MM, and Dee AN (1997a). Clonal versus polyclonal Epstein-Barr virus infection in nasopharyngeal carcinoma cell lines. Lab Invest 76:793-798.

Lin CT, Dee AN, Chen W, and Chan WY (1994). Association of Epstein-Barr virus, human papilloma virus, and cytomegalovirus in nine nasopharyngeal carcinoma cell lines. Lab Invest 71:731-736.

Lin CT, Lin CR, Tan GK, Chen W, Dee AN, Hsu MM, and Chan WY (1997b). The mechanism of Epstein-Barr virus infection in nasopharyngeal carcinoma cells. Am J Pathol 150:17451756.

Lin CT, Wong Cl, Chan WY, Tzung KW, Ho JK, Hsu MM, and Chuang SM (1990). Establishment and characterization of two nasopharyngeal carcinoma cell lines. Lab Invest 62:713724.

Lin TM, Hsu MM, Chen KP, Chiang TC, Jung PF, and Hirayama T (1971). Morbidity and mortality of cancer of the nasopharynx in Taiwan. Gann Monogr 10:137-144.

Mahe Y, Hirose K, Clausse B, Chouaib S, Tursz T, and Mariame $B$ (1992). Heterogeneity among human nasopharyngeal carcinoma cell lines for inflammatory cytokines mRNA expression levels. Biochem Biophys Res Commun 187:121126.

Massague J (1990). Transforming growth factor- $\alpha$. A model for membrane-anchored growth factors. J Biol Chem 265: 21393-21396.

Miller WE, Earp HS, and Raab-Traub N (1995). The EpsteinBarr virus latent membrane protein 1 induces expression of the epidermal growth factor receptor. J Virol 69:4390-4398.

Nemerow GR and Cooper NR (1981). Isolation of EpsteinBarr virus and studies of its neutralization by human $\lg G$ and complement. J Immunol 127:272-277.

Niedobitek G, Hansmann ML, Herbst H, Young LS, Dienemann D, Hartmann CA, Finn T, Pitteroff S, Welt A, Anagnostopoulos I, Friedrick R, Lobeck H, Sam CK, Araujo I, Rickinson AB, Stein H (1991). Epstein-Barr virus and carcinoma: Undifferentiated carcinoma but not squamous cell carcinomas of the nasopharynx are regularly associated with the virus. J Pathol 165:17-24.

Nishida K, Sotozono C, Adachi W, Yamamoto S, Yokoi N, and Kinoshita S (1995). Transforming growth factor-b1, -b2, and -b3 mRNA expression in human cornea. Curr Eye Res 14:235-241.

Paludan K and Thestrup-Pedersen K (1992). Use of the polymerase chain reaction in quantification of Interleukin 8 mRNA in minute epidermal samples. J Invest Dermatol 99:830-835.

Pearson GR (1993). Epstein-Barr virus and nasopharyngeal carcinoma. J Cell Biochem Suppl 17F:150-154.

Santini J, Formento JL, Francoual M, Milano G, Scheneider M, Dassonville O, and Demard F (1991). Characterization, quantification, and potential clinical value of the epidermal growth factor receptor in head and neck squamous cell carcinomas. Head Neck 3:132-139.

Sixbey JW and Yao QY (1992). Immunoglobulin A-induced shift of Epstein-Barr virus tissue tropism. Science 255:15781580.

Takada K, Shimizu N, Tanabe-Tochikura A, and Kuroiwa Y (1995). Pathogenic role of Epstein-Barr virus in human cancer. Intervirology 38:214-220. 
Tanner JE and Menezes J (1994). Interleukin-6 and EpsteinBarr virus induction by cyclosporine $A$ : Potential role in lymphoproliferative disease. Blood 84:3956-3964.

Thalmeier K, Merbner P, Reisbach G, Hultner L, Mortensen BT, Brechtel A, Oostendorp RAJ, and Dormer P (1996). Constitutive and modulated cytokine expression in two permanent human bone marrow stromal cell lines. Exp Hemato 24:1-10.

Untawale S, Zorbas MA, Hodgson C, Coffey RJ, Gallick GE, North SM, Wildrick DM, Olive M, Blick M, Yeoman LC, and Boman BM (1993). Transforming growth factor- $\alpha$ production and autoinduction in a colorectal carcinoma cell line (DiFi) with an amplified epidermal growth factor receptor gene. Cancer Res 53:1630-1636.

Wang AM, Doyle MV, and Mark DF (1989). Quantitation of mRNA by the polymerase chain reaction. Proc Natl Acad Sci U S A 86:9717-9721.
Wilkinson M (1988). RNA isolation: A mini-prep method. Nucleic Acids Res 16:10933-10934.

Wolf H, Bogedain C, and Schwarzmann F (1993). EpsteinBarr virus and its interaction with the host. Intervirology 35:26-39.

Zheng X, Hu L, Chen F, and Christensson B (1994). Expression of Ki67 antigen, epidermal growth factor receptor and Epstein-Barr virus-encoded latent membrane protein (LMP1) in nasopharyngeal carcinoma. Eur $\mathrm{J}$ Cancer B Oral Oncol 30B:290-295.

Zur Hausen $H$, Schulte-Holthaugen $H$, Klein G, Henle G, Henle W, Clifford P, and Santesson L (1970). EBV DNA in biopsies of Burkitt's tumours and anaplastic carcinomas of the nasopharynx. Nature 228:1956-1958. 